RUNNING HEAD: SEEKING MATERNAL SUPPORT IN MIDDLE CHILDHOOD

Dujardin, A., Santens, T., Braet, C., De Raedt, R., Vos, P., Maes, B., \& Bosmans, G. (in press). Middle childhood support-seeking behavior during stress: Links with self-reported attachment and future depressive symptoms. Child Development

Middle childhood support-seeking behavior during stress: Links with self-reported attachment and future depressive symptoms

Authors:

Adinda Dujardin ${ }^{1}$, Tara Santens ${ }^{1}$, Caroline Braet ${ }^{3}$, Rudi De Raedt ${ }^{2}$, Pieter Vos ${ }^{1}$, Bea Maes ${ }^{1}$, Guy Bosmans ${ }^{1}$

\footnotetext{
${ }^{1}$ Parenting and Special Education Research Unit, University of Leuven

${ }^{2}$ Department of Experimental Clinical and Health Psychology, Ghent University

${ }^{3}$ Department of Developmental, Personality, and Social Psychology, Ghent University
} 
Correspondence should be sent to Adinda Dujardin, Parenting and Special Education

Research Unit, KU Leuven, Leopold Vanderkelenstraat 32, box 3765, 3000 Leuven, Belgium.

E-mail: adinda.dujardin@ppw.kuleuven.be, Tel. : + (32)(0)16/326068

\title{
Acknowledgement
}

This study was supported by Grant G.0934.12 of the Research Foundation Flanders (FWO), and Grants OT/12/043 and CREA/12/004 from the Research Fund KU Leuven, Belgium. The authors thank Emma Goldblum for proofreading the manuscript.

\begin{abstract}
This study tested whether more anxious and avoidant attachment is linked to decreased support-seeking behavior towards mother during stress in middle childhood, and whether decreased support-seeking behavior enhances the impact of experiencing life events on the increase of depressive symptoms 18 months later. Ninety-eight 8 to 12 year old children's anxious and avoidant attachment and depressive symptoms were assessed with questionnaires. Children's support-seeking behavior was observed through measuring time children waited before calling for mother's help while carrying out a distressing task. Results supported the hypothesis that more anxiously or avoidantly attached children waited longer before seeking maternal support. Moreover, waiting longer was related to increased depressive symptoms at follow-up in children who were exposed to more life events.
\end{abstract}

Key words: Attachment, Support-seeking, Stress, Depressive symptoms, Middle childhood 


\section{Middle childhood support-seeking behavior during stress: Links with self-reported attachment and future depressive symptoms}

Stress is a significant risk factor for the development of psychopathology in childhood and adolescence, especially when it is not adequately regulated (Compas, Connor-Smith, Saltzman, Thomsen, \& Wadsworth, 2001). In this regard, research shows that maternal inadequacy to help children regulate stress in middle childhood increases children's risk to develop depression from adolescence onwards (Mezulis, Hyde, \& Abramson, 2006). This emphasizes the developmental importance of stress-regulating interactions with parents in middle childhood. Attachment theory underscores the idea that the parent-child relationship plays an important role in children's stress-regulation (e.g., Thompson, 1994), and the idea that stress-regulatory processes within parent-child relationships influence the development of psychopathology. According to this theory, children's repeated experiences with parental support in times of stress lead to the development of expectations regarding parental availability and support. These expectations influence whether or not children will seek attachment figures' support in future times of stress (Bowlby, 1969). This way attachment theory explains how children's repeated interactions with caregivers form a critical context for future stress-regulatory processes, and the subsequent development of psychopathology. Although this theoretical assumption explains the fundamental relevance of attachment relationships in models of developmental psychopathology (Steele \& Steele, 2014), little research has focused specifically on whether children's support-seeking behavior in times of stress is linked to children's attachment expectations, and whether it influences the risk to develop psychopathology. 
Although attachment theory would suggest that such mechanisms should be found in all ages, it has been argued that middle childhood is a crucial developmental period to focus on for this type of research because maladaptive supportive processes at this age have significant impact in adolescence on, for example, the development of depression (Mezulis et al., 2006; Kerns \& Brumariu, in press). Therefore, the current study aimed to investigate (1) whether middle childhood self-reported anxious and avoidant attachment is related to reduced support-seeking behavior towards mother in times of stress, and (2) whether reduced support seeking puts children at risk for increased depressive symptoms 18 months later conditional upon experiencing distressing life events in between measurement times. We focused on the mother-child attachment relationship, because this is the most important attachment relationship in middle childhood (Kerns, Abraham, Schlegelmilch, \& Morgan, 2007), and because research suggests that mother-child supportive interactions are especially important in modulating the impact of stress on the development of depression (Mezulis et al., 2006).

\section{Research Aim 1: Attachment Expectations and Support-Seeking.}

The idea of support-seeking as a stress-regulating strategy is central to attachment theory. Bowlby (1969) stated that, to promote survival, infants are born with a repertoire of behaviors organized in an 'attachment behavioral system'. This system's main goal is to seek caregivers' proximity and support in times of stress. When stress activates this attachment behavioral system, children will seek attachment figure's proximity to receive care and support. However, once feeling sufficiently safe, activation of the attachment behavioral system and its support-seeking behaviors is supposed to stop. Bowlby thus viewed proximity and support seeking as a primary inborn stress-regulating strategy. But apart from that, he also assumed that the extent to which children continue to engage in such support-seeking behavior depends on their particular history of attachment experiences (Bowlby, 1969; 1973; Cassidy, 1994). When children consistently experience that seeking support leads to parental 
responsiveness and successfully restores a sense of felt security - typical for secure attachment (Sroufe \& Waters, 1977) - they learn that seeking support is a useful stressregulating strategy, and their innate tendency to seek caregivers' support during stress is reinforced (see Kandel, 1999). Conversely, when children experience that seeking support does not (consistently) lead to responsiveness and felt security - typical for insecure attachment - they are less likely to rely on proximity-seeking as an emotion regulation strategy, but instead develop alternative stress-regulation strategies (see Cassidy, 1994; Main, 1990; Main, Kaplan, \& Cassidy, 1985). Attachment literature describes two alternative strategies characterized by differences in children's need for attachment figure proximity and support-seeking behavior.

First, insecure-avoidant children, who experienced that support-seeking consistently resulted in unresponsiveness or rejection by the attachment figure (e.g., Ainsworth, Blehar, Waters, \& Wall, 1978; Grossmann, Grossmann, Spangler, Suess, \& Unzner, 1985), are likely to minimize the importance of the caregiver as a source of support, and hence their apparent need for attachment figure proximity and support (Cassidy, 1994). In observational research, avoidantly attached infants are found to display little interest in, and even avoid proximity with their mother upon reunion (Ainsworth et al., 1978; Main \& Cassidy, 1988). Similar dynamics have been documented in adult research, where self-reported attachment avoidance is found to be related to a reduced automatic tendency to seek attachment figures' proximity (Dewitte, De Houwer, Buysse, \& Koster, 2008), and with less support-seeking behavior to the attachment figure in romantic relationships (Collins \& Feeney, 2000; Fraley \& Shaver, 1998).

Second, insecure-ambivalent children, who experienced inconsistent parental responsiveness (e.g., Ainsworth et al., 1978; Grossmann et al., 1985) are likely to heighten their need for proximity to and support from the attachment figure (Cassidy, 1994). In observational research, these children typically display an increased and sustained need for 
close proximity to their mother, however, they do so in an ambivalent way, displaying both clinging behavior as well as anger and hostility towards their mother, sometimes accompanied by moderate avoidance of her (Ainsworth et al., 1978; Main \& Cassidy, 1988). Similarly, in adults the pattern of results is also quite unclear. Whereas adult self-reported attachment anxiety is found to be related to a heightened automatic tendency to seek attachment figures' proximity (Dewitte et al., 2008), and to increased indirect support-seeking behavior such as nonverbally signaling distress (e.g., crying, pouting, sulking), it was found to be unrelated to direct requests for support from the romantic partner (Collins \& Feeney, 2000; Fraley \& Shaver, 1998). Thus, research in both infants and adults suggests that although more anxiously attached individuals have an increased need for attachment figure proximity and support, this does not necessarily translate into straightforward support-seeking behavior.

Taken together, attachment theory and research suggest that insecure attachment inhibits or interferes with effective support-seeking (see Mikulincer \& Shaver, 2008), both in infancy and adulthood. To date, however, this theory has not been validated in middle childhood. Therefore, the first aim of the current study was to investigate whether, in middle childhood, less secure attachment expectations are related to reduced support-seeking towards mother during a stressful situation.

\section{Research Aim 2: Stress, Support-Seeking, and Development of Depressive symptoms.}

Depression is one of the most common and most alarming psychiatric disorders during adolescence (see e.g., Lee, Hankin, \& Mermelstein, 2010). Moreover, even subclinical depressive symptoms are associated with impaired functioning (Cuijpers \& Smit, 2002; Lewinsohn, Solomon, Seeley, \& Zeiss, 2000). Therefore it is important to identify factors contributing to the development of depressive symptoms. Stressful life events constitute a risk factor for the development of psychopathology, however, specifically the inadequacy to cope 
with these life events is thought to put children and adolescents at elevated risk to develop psychopathology (see Compas et al., 2001) and depressive symptoms (see Mezulis et al., 2006). Attachment theory suggests that secure attachment expectations protect against the pathogenic effects of stress, because they increase the chance that children seek caregivers' support in times of stress (Ainsworth, 1973; Bowlby, 1969; 1973) suggesting that seeking parental support is a protective factor against the development of depressive symptoms. Supporting this hypothesis, attachment research in young children suggests that supportseeking towards mother is adaptive (e.g., Easterbrooks, Davidson, \& Chazan, 1993; DuboisComtois, Moss, Cyr, \& Pascuzzo, 2013). However, since a lack of maternal support in times of stress in middle childhood is a significant risk factor for future depression (Mezulis et al., 2006), it can be hypothesized that particularly middle childhood support-seeking behavior towards mother in times of stress is of crucial developmental importance. Surprisingly, however, no studies to date have addressed this question in middle childhood. Therefore, the second aim of the current study was to investigate the hypothesis that if children can more easily seek maternal support, it can serve as a protective factor against showing increased levels of depressive symptoms conditional upon the experience of stressful life events during the follow-up period.

\section{The current study}

An experimental observational procedure was used to assess children's supportseeking behavior during stress in middle childhood. This procedure was developed to elicit observable and quantifiable support-seeking behavior towards mother in middle childhood (Bosmans, Braet, Heylen, \& De Raedt, 2015). In accordance to the proposition that social comparison and hurt pride are particularly distressing and activate a need for parental support in this age group (see Bosmans et al., 2015; Gunnar, Talge, \& Herrera, 2009; Mayseless, 2005), children were given an unsolvable puzzle described as easily solved by their peers. 
Based on Bowlby's (1988) assumption that distressed insecurely attached children seek less maternal support and based on abovementioned observations that both insecure-ambivalently and avoidantly attached children show impaired support seeking, Bosmans et al. (2015) operationalized support seeking as time distressed children waited to call for their mother's help to solve the puzzle. This way, Bosmans et al. (2015) found support for slower support seeking in children with less self-reported confidence in maternal support. Using this procedure, we tested the hypotheses that (1) less secure attachment expectations are related to slower support-seeking (ringing the bell), and that (2) children with slower support-seeking towards mother in middle childhood have a higher chance to develop more depressive symptoms in response to stressful life events during an 18 months follow-up period.

During the procedure children's level of skin conductance (SC) was continuously assessed. SC is a measure of sympathetic nervous system (SNS)-activity, (e.g., Larsen, Berntson, Poehlman, Ito, \& Cacioppo, 2010), representing participants' physiological level of stress. This measure was included for several reasons. (1) It served as a valid manipulation check. The stress-inducing effect of the puzzle procedure was demonstrated by comparing children's stress level during the procedure with their baseline stress-level. (2) It allowed controlling for potential confounding effects of individual differences in stress-responsivity on children's support-seeking behavior. More specifically, it was well possible that children who experienced more stress due to the procedure would seek support faster, which could mask the effect of attachment on their support-seeking behavior. (3) Relatedly, it allowed investigating whether attachment was linked to children's stress-responsivity. This in order to rule out the possibility that the link between attachment and children's support-seeking behavior would in fact be the results of attachment-related differences in stress-responsivity to the procedure. This is an important alternative explanation to rule out because in some studies evidence has been found that insecure attachment is related to increased physiological 
responses to stress (Dewitte, De Houwer, Goubert, \& Buysse, 2010; Diamond, Hicks, \& Otter-Henderson, 2006; Kim, 2006; Luijk et al., 2010; Maunder, Lancee, Nolan, Hunter, \& Tannenbaum, 2006).

Additionally, since children's physiological stress-responses have been found to undergo significant changes throughout the transition to puberty (Hankin, Badanes, Abela, \& Watamura, 2010; Gunnar, Wewerka, Frenn, Long, \& Griggs, 2009), and since in the current study's age group striking differences might exist in pubertal development, the current results were also controlled for possible effects of pubertal status.

\section{Method}

\section{Participants}

Ninety-eight children (46 boys, 52 girls) and their mothers participated in the study, with ages ranging from 8 to $12(M=10.39, S D=.92)$. All children participated with their biological mother, except for one child whose mother was an adoptive mother. In this group, $87.8 \%$ of the children had married or cohabitating parents, $6.1 \%$ had divorced parents, and $6.1 \%$ came from blended families. Regarding mothers' and fathers' level of education, $17.3 \%$ and $35.7 \%$ had a high school degree, $48.0 \%$ and $35.7 \%$ had a post-high school technical training or a bachelor degree, and $34.7 \%$ and $28.6 \%$ had a university master degree, respectively.

Forty-eight (20 boys, 28 girls) children from this sample also volunteered to participate in the follow-up part of the study. Ages ranged from 10 to $14(M=11.98, S D=$ 1.02) at follow-up. A multivariate ANOVA with age and the continuous variables as dependent variables revealed no drop-out effect, $F(7,73)=1.07, p=.393$. Also, in the univariate follow-up analyses, none of the effects reached significance at $p<.05$. Moreover, 
no sociodemographic differences were found between the children who dropped out or not $\left(\chi^{2} \mathrm{~s}<4.81, p \mathrm{~s}>.187\right)$

\section{Procedure}

Participants were recruited by distributing informative flyers in elementary schools to 4th, 5th, and 6th grade children and parents. Parents that replied positively on the flyer were contacted by telephone to invite them for participation, and to schedule a testing appointment. After being informed about the study, $74.4 \%$ of the contacted participants volunteered to participate. One hundred and fifteen children and their mothers were invited to participate in the study. However, data from 17 participants were removed from the analyses, because they could not be used in light of the current study's research question (14 participants did not follow the puzzle rules and solved the puzzle and three participants' mother gave wrong instructions during Reunion 1). Consequently, the final sample consisted of 98 children. The participants that were removed from analyses did not differ significantly on depressive symptoms, attachment anxiety, or attachment avoidance on Time 1 ( $p$ s > . 205).

Upon arrival in the lab, first, mother entered the test room alone and was informed about the entire research procedure, about her role in this procedure, about the fact that the puzzle was unsolvable (which she could not tell the child), and about the fact that this procedure was assumed to be stressful for the child. When mother gave her informed consent, the child entered and was informed about the general goal of the study (i.e., investigate how children respond to a stressful situation), the physiological measurement apparatus that would be applied, and the tasks that he/she would have to complete. Children were also informed about their right to decline participation at any point during the procedure.

First, physiological measurement equipment was applied to the child in the presence of mother. Next, the mother left the lab and remained present in a separate room. Before the 
start of the actual research procedure, the child stayed in the room with the experimenter for approximately 30 minutes to acclimatize to the physiological measurement equipment. In the meanwhile the child completed a series of questionnaires.

Next, in order to register a baseline measurement of the physiological parameters (Baseline Phase, BL), the child was left alone for 5 minutes and instructed to relax and watch a movie of desolate beaches with calming background music. Next, the researcher reentered the room and the actual research procedure started. This was a shortened version of Bosmans et al.'s (2015) procedure, which was adjusted because of the total length en complexity of the current study's procedure. First, the experimenter introduced the puzzle task, taken from the Rush Hour Traffic Jam Puzzle ® which was used before to induce distress in middle childhood by Eldar, Ricon, and Bar-Haim (2008). In this task, plastic cars and trucks need to be moved in such a way that allows the red car, blocked by traffic, to find a way out of the traffic jam. The rules were explained, and the child solved an easy practice version with the researcher. Then, the child received the unsolvable puzzle to work on for 15 minutes. The experimenter told that this was more than enough time since most peers were able to solve it within 5 minutes. The child was informed that after 5 minutes, mother would come in and offer help if needed. A digital chronometer informing the child about the time spent on the task was placed in front of the child on a computer screen. Stress-induction thus consisted of solving an unsolvable task under time pressure while experiencing the pressure of social comparison with peers.

The child worked alone on the puzzle for five minutes (Puzzle Phase 1). After 5 minutes, their mother entered the room (Reunion 1). Mother was instructed to behave as if she was unaware that the puzzle task was unsolvable, and was instructed to help by giving short verbal suggestions or a manual suggestion (moving a car herself). The Reunion was included to make sure that all mothers were linked to the meaning 'providing help'. Before leaving the 
room, the mother gave the child a door bell and the instruction that if the child needed her, he/she should ring the bell and mother would come immediately. The child was able to test the bell which gave visual (light on the bell) and auditory (the sound of the ringing bell in the hallway could be heard in the test room) feedback. The child continued with the puzzle alone after the mother left the room (Puzzle Phase 2). Following the procedure designed by Bosmans et al. (2015) and following their finding that also time before calling mother a second time was linked with attachment, the mother was asked not to enter the room before the child rang the bell a second time to see whether the effects replicated within the procedure. The rest of the procedure depended on the child's support-seeking behavior. When the child rang the bell two times before the end of the available puzzle time (i.e. 15 minutes), mother entered the room. When the child did not ring, or only rang the bell once, mother entered the room anyway after 15 minutes. In both cases, mother assisted the child for another three minutes (Reunion 2). Afterwards, the experimenter entered the room and inquired about why the child was unable to find a solution (manipulation check). All children were surprised that the puzzle was unsolvable and that the experimenter misled them. Finally, the experimenter debriefed the child, and gave the child two movie tickets for their participation. A visual overview of the study procedure is given in Figure 1. Children's level of SC was continuously registered throughout the procedure, and the entire procedure was video-taped. Before leaving the lab, mothers were asked if the researchers could contact them again for participation in a follow-up study.

Approximately 18 months $(M=18.67, S D=3.27$, Range $12-22$ months $)$ after testing, parents received an e-mail invitation for their child to participate in the follow-up study. The e-mail included a personalized electronic link to an online survey. Parents were asked to let their children complete this survey alone in a quite space. Several invitation reminders were sent throughout a four-month period after the first invitation. At every invitation, parents had 
the opportunity to opt-out for future reminders. Children filled out the survey approximately 21 months $(M=21.01, S D=3.39$, Range $14-25$ months $)$ after participating in the first part of the study. The local university's ethical committee approved the entire procedure.

\section{Calculation of the Variable 'Time to Support-Seeking'.}

While we originally planned to use the time between Reunion 1 and Bell 1 (for children who rang the bell) or Reunion 2 (for children who did not ring) as an indicator of children's support-seeking speed, we were concerned that this indicator would be influenced by variation in the duration of Reunion 1 . More specifically, despite the fact that all mothers were instructed to have a short reunion with their child, some mothers stayed in for several minutes $(41 "-355 " ; M=131.85 S D=61.01)$. Consequently, for some children there was not much time left between Reunion 1 and the end of the Puzzle procedure (15') to ring the bell. Possibly, some children who did not ring the bell would have rang it if they had more time left after Reunion 1. In line with our concerns, results of a logistic regression to predict the occurrence of Bell 1 by the Duration of Reunion 1 showed that the longer reunion 1, the lower the chance that children rang the bell $\left(\chi^{2}(1)=3.47, B=-.01, S E_{B}=.004, p=.062\right)$.

Consequently, Duration of Reunion 1 might have been a source of error variance in the variable representing children's speed of support-seeking, affecting the correlation with other predictors. To control for this variance, we calculated a new variable 'Time to SupportSeeking' as described below.

First, for Duration of Reunion 1, all cases deviating more than two standard deviations from the mean were identified. For five participants, Reunion 1 lasted more than two standard deviations longer than average (range 4'20" - 5'55”). These participants were removed for calculating the Time to Support-Seeking variable. For the remaining participants, the maximal Duration of Reunion 1 was four minutes. In this case, the remaining time after Reunion 1 
during which the child could ring the bell was six minutes. This was defined as the end of the procedure for all participants. Thus, all participants who did not ring the bell within six minutes after Reunion 1 received this value (360 seconds) for the variable Time to SupportSeeking. The rationale behind this was that the participant for which Reunion 1 was the longest (four minutes), and who had only six more minutes to ring, could have rang if he/she would have had more time. In our sample 23 participants were given this maximal value of 360 seconds, and within this group 19 did not ring anymore after this 360 seconds period. Confirming that this alternative calculation solved the impact of duration during Reunion 1 on time to support seeking, the correlation between duration of Reunion 1 and the new Time to Support Seeking was no longer significant $(r=.03 ; p=.778)$. Although this recalculation was done to obtain more straightforward data, all analyses were also repeated with the original variable 'Time between Reunion 1 and Bell 1 or Reunion 2', and this did not lead to substantially different results for both research questions (unless specified otherwise in the results section), even after controlling for duration of Reunion 1.

The variation of duration during Reunion 1 had an additionally reducing effect on the time children had left to call mother a second time after Bell 1. Because this second indicator of proximity seeking was not crucial for our research goal (see also the results of Bosmans et al., 2015), we decided not to use this for the analyses.

\section{Measures}

Skin conductance. To assess children's stress-level during the procedure, their skin conductance was continuously registered using Dream® ${ }^{\circledR}$ technology (Medatec Dream conductance amplifying and measuring module, Medical Data Technology, Brussels, Belgium), at a sampling rate of $200 \mathrm{~Hz}$, which registers SC using an exosomatic alternating current (AC) method with constant current $(1,5$, or $25 \mu \mathrm{A}$, periodically adapted depending on 
the individual's measured base impedance to optimize resolution). To measure SC, two reusable $8 \mathrm{~mm}$ circular snap style $\mathrm{Ag}-\mathrm{AgCl}$ electrodes (type SE-35, J\&J Engineering) embedded into a hook and loop fastener band were used. To reduce the impact of movement SC was measured on the non-dominant hand and children were asked not to use that hand while solving the puzzle. The electrodes were applied to the volar (palmar) side of the medial phalanges of the middle- and index finger using a salt- and chloride-free, hypoallergenic electrolyte paste (Spectra® 360 electrolyte gel, Parker Laboratories, Inc.). Based on the continuous SC signal, an average SC was calculated for each 10 second epoch of the test procedure, representing the participant's average level of SNS-activity (Dawson, Schell, \& Filion, 2007; Zisner \& Beauchaine, 2014).

Anxious and Avoidant attachment. At both time points, the participants completed the ECR-RC (Brenning, Soenens, Braet, \& Bosmans, 2011), a child version of the Experiences in Close Relationships Scale-Revised (ECR-R, Fraley, Waller, \& Brennan, 2000). The ECR-RC assesses self-reported avoidant and anxious attachment dimensions. The Attachment anxiety scale (18 items) taps into feelings of fear of abandonment and strong desires for interpersonal merger (e.g., I worry about being abandoned). The Attachment avoidance scale (18 items) taps into discomfort with closeness, dependence, and intimate selfdisclosure (e.g., I prefer not to show how I feel deep down). Items are rated on a 7-point Likert scale ranging from (1) 'not at all' to (7) 'very much'. The children were asked to rate each of the items with regard to their mother. Both subscales have strong internal consistency and validity (Brenning et al., 2011). In the current study, at time point 1 Cronbach's alpha was .82 and .86 for Attachment Anxiety and -Avoidance, respectively; and at follow-up it was .90 and .93 , respectively. Mean scores were calculated for each scale separately.

Pubertal status. At time point 1, the participants completed a Dutch translation of the Pubertal Development Scale (PDS, Petersen, Crockett, Richards, \& Boxer, 1988) to assess 
pubertal status. Participants are asked to respond to five questions - for boys and girls separately - about their physical development (e.g., growth spurt, beard growth, breast development), by rating whether a physical change has occurred yet on a scale from 1 (not started/happened yet) to 4 (development completed). The PDS has been found to have good validity and reliability (Petersen et al., 1988; Shirtcliff, Dahl, \& Pollak, 2009), including evidence that PDS scores are strongly associated with physical examination of pubertal development. In the current study, Cronbach's alpha was .73. A sum score was calculated.

Depressive symptoms. At both time points, the participants completed a Dutch translation of The Center for Epidemiologic Studies Depression Scale (CESD, Radloff, 1977), a 20-item questionnaire that measures 9 depressive symptoms: sadness, loss of interest (anhedonia), appetite, sleep, thinking/concentration, guilt, fatigue, movement, and suicidal ideation. Items are rated on a 4-point scale ranging from 0 , 'not at all or less than one day', to 3, 'nearly every day for 2 weeks'. The reliability and validity of the CES-D has been established in both children and adolescents, showing good internal consistency and construct validity, and distinguishing children with clinically significant depressive symptoms from healthy children (Poulin, Hand, \& Boudreau, 2005). In the current study, Cronbach's alpha was .76 at time point 1 , and .79 at time point 2 . A sum score was calculated.

Experienced Life Events. At follow-up, the participants completed the Questionnaire of Life Events - Adolescent report (QLE-A, Claus, 2004). This is an adapted version of the Questionnaire of Life Events (QLE-P, Veerman, ten Brink, van der Horst, \& Koedoot, 1993), which is a Dutch parent-report questionnaire that reliably and validly assesses potential stressful life-events in youth. The QLE-A is used to systematically assess events that might happen in families, and which could be perceived as potentially stressful because they require a certain amount of adaptability and transition from the normal course of daily life. The QLEA consists of a list of 37 potentially stressful negative, neutral and positive events that can 
happen families (e.g. birth of a sibling, moving, illness), and which participants could have experienced in their primary caregiving environment. For each event, the participants are asked whether or not the event under question happened to them since the first test moment, using a yes/no format. A sum score was calculated with higher scores reflecting more events.

\section{Results}

\section{Preliminary Analyses}

Descriptive statistics. On the questionnaire data, $0.12 \%$ of the responses were missing at time point 1 , and $0.17 \%$ at follow-up. Data were missing at random (Little MCAR Test: $\left.\chi^{2}(41)=26.84, p=.957\right)$. Missing data were listwise deleted, and no total score was calculated on questionnaires that contained missing responses. For descriptives, links with age and gender, and correlations between the study's main variables, see Table 1. For SC, data were missing for eight participants, due to technical errors with the measurement device, leaving 90 participants for the SC analyses.

Manipulation check. To check for the stress-inducing effect of the puzzle procedure, we investigated whether children's SC was increased during the puzzle procedure as compared to the Baseline Phase (BL). This was investigated with regard to two different time points during the puzzle procedure. First, to see whether the puzzle task was stress-evoking, we investigated (1) the change in SC from the End of the BL (i.e., the final 30" of the BL) to the End of Puzzle Phase 1 (i.e., the final 30" of Puzzle Phase 1). Second, to see whether stress was still elevated at the moment of support-seeking or at the end of the procedure (for the children who did not seek support), we investigated (2) the change in SC from the End of the BL to the End of Puzzle Phase 2 (i.e., the final 30" before Bell 1 for the children who rang the bell, and the final 30 " before the defined end of the procedure for the children who did not ring the bell within the defined end of the procedure, set at 360 seconds). Therefore, two 
repeated measures ANOVA's were conducted with SC as dependent variable, and time (BL, Puzzle Phase 1 and BL, Puzzle Phase 2, respectively) as within-subjects variable. Results showed that SC significantly increased from the End of the BL $(M=12.93, S D=8.25)$ to the End of Puzzle Phase $1(M=14.48, S D=9.37), F(1,87)=20.55, \mathrm{p}<.001, \eta_{p}{ }^{2}=.19$, and to the End of Puzzle Phase $2(M=14.89, S D=9.57), F(1,81)=22.87, \mathrm{p}<.001, \eta_{p}{ }^{2}=.22$. This increase was independently from Age, Gender, and Pubertal Status. These results suggest that the procedure induced stress in this sample.

Additionally, we investigated whether these increases in SC during the task as compared to BL were related to children's attachment expectations. This in order to rule out the possibility that attachment-related differences in support-seeking behavior could in fact be explained by attachment-related differences in stress-responsivity to the procedure. For this purpose, two new variables were calculated. First, we calculated a variable labeled 'Stress Increase from BL to End Puzzle Phase 1' as the difference score of SC in the final 30" of Puzzle Phase 1 minus SC in the final 30" of the BL. Second, we calculated a variable labeled 'Stress Increase from BL to End Puzzle Phase 2' as the difference score of SC in the final 30" of Puzzle Phase 2 minus SC in the final 30" of the BL. Higher scores on these variables represent a stronger increase in SC. Attachment Anxiety and Attachment Avoidance were unrelated to both the Stress Increase from BL to End Puzzle Phase $1, r(88)=-.06, p=.580$, and $r(88)=-.10, p=.338$, respectively, and to the Stress Increase from BL to End Puzzle Phase 2, $r(82)=.08, p=.464$, and, $r(82)=-.04, p=.754$, respectively.

Check for potential predictors of 'Time to Support-Seeking'. Before investigating the current study's research question regarding whether attachment is linked to children's speed of support-seeking, we first checked for potential predictors of this variable. This in order to identify potential confounding variables that should be controlled for. Time to SupportSeeking (Range $=7$ - 360 seconds) was unrelated to both Age and Gender (see Table 1), and 
to Stress Increase from BL to Puzzle Phase $2, r(80)=.004, p=.969$, but it was significantly correlated with Pubertal Status, (see Table 1), with a more advanced pubertal development being linked to a longer waiting time before seeking support. Therefore, Pubertal Status was added as a control variable in the analyses investigating predictors of Time to ProximitySeeking. However, all analyses were also repeated without control variables, and this did not lead to substantially different results.

\section{Research Aim 1: Attachment Anxiety, Attachment Avoidance, and Time to Support- Seeking}

First, correlations were calculated between Time to Support-Seeking and Attachment Anxiety/Attachment Avoidance. Results revealed that higher scores on both Attachment Anxiety and Attachment Avoidance were linked to a longer waiting time before seeking support (see Table 1). Next, partial correlations were calculated to control for Pubertal Status. The link between Time to Support-Seeking and Attachment Anxiety or Attachment Avoidance, remained significant, $r(88)=.27, p=.010$, and, $r(88)=.23, p=.026$, respectively. Repeating these analyses with the original behavioral variable 'Time between Reunion1 and Bell1 or Reunion2' did not substantially change these results, although the link between Attachment Avoidance and 'Time between Reunion1 and Bell1 or Reunion2', controlling for Pubertal Status was marginally significant.

\section{Research Aim 2: Time to support-seeking, Life events, and Follow-up Depressive symptoms}

To investigate the role of speed of support-seeking in predicting increased depression at follow-up, the partial correlation was calculated between Time to Support-Seeking and Follow-up Depressive symptoms, controlling for Depressive Symptoms at Time Point 1. Moreover, since there was variation in the time interval between the first test moment and the 
follow-up test moment, Time Interval was entered as a control variable in this analysis. This partial correlation was non-significant, $r(37)=-.002, p=.992$.

To investigate the interaction between Time to Support-Seeking and Experienced Life Events in predicting Follow-Up Depressive Symptoms, moderation analysis was performed using Hayes' (2013) PROCESS tool for SPSS (Model 1), while controlling for Depressive Symptoms at Time Point 1 and for Time Interval. This analysis revealed a significant interaction effect between Time to Support-Seeking and Experienced Life Events, $F(1,35)=$ $7.83, p=.008$. To evaluate the meaning of this interaction effect, data for plotting were generated following the recommendations of Aiken and West (1991) (see Figure 2), and we performed single slope analysis to assess the significance of the slopes for both the lower and higher values of the moderator $(\mathrm{M}-1 \mathrm{SD}, \mathrm{M}+1 \mathrm{SD})$. The results of this analysis showed a significant positive link between Time to Support-Seeking and Follow-up Depressive Symptoms for higher scores of Experienced Life Events, $B=0.03, S E_{B}=0.01, p=.019$, and a marginally significant negative link between Time to Support-Seeking and Follow-up Depressive Symptoms, $B=-0.02, S E_{B}=0.01, p=.055$, for lower scores of Experienced Life Events. Furthermore, for children with higher scores on Time to Support-seeking (M+1SD), higher Experienced Life Events scores were linked with more Depressive Symptoms, $B=$ 0.93, $S E_{B}=0.29, p=.003$. No Experienced Life Events scores effects on Depressive Symptoms were found for children with lower scores on Time to Support-Seeking (M-1SD), $B=-0.36, S E_{B}=0.29, p=.223$. Controlling for age did not change the results.

\section{Discussion}

The current study investigated in middle childhood (1) whether, during stress, children with less secure attachment expectations seek maternal support more slowly, and (2) whether children who seek maternal support more slowly have a higher risk to develop increased 
levels of depressive symptoms when exposed to more stressful life events. For this purpose, children's self-reported anxious and avoidant attachment and time before seeking maternal support during a distressing task was assessed, and during a longitudinal follow-up children reported on their past distressing life-events and current depressive symptoms. Results suggested that although the procedure was distressing independent of children's self-reported attachment, (1) children who reported to be more anxiously or more avoidantly attached waited longer before seeking maternal support. Moreover, (2) waiting longer before seeking support during this procedure was related to increased depressive symptoms at follow-up if children had experienced more life events.

The finding that the puzzle task increased skin conductance levels is in line with children's self-report about distress experienced during this task (Bosmans et al., 2015), and supports the validity of the procedure in inducing age-relevant distress. The increase was not related to children's attachment expectations. This contradicts previous infant and adult research on the link between attachment and physiological stress responses even though the sample size allowed testing this effect with adequate power $(1-\beta=.80)$. However, results are difficult to compare because these studies measured cortisol reactivity as outcome in different procedures (e.g., Dewitte et al., 2010; Luijk et al., 2010). Given the relevance of comparison to peer competence for middle childhood self-esteem (Gunnar et al., 2009) it is not unlikely that the procedure increased skin conductance level in all children to the extent that too little variance was left to explain by attachment. Nevertheless, it remains important to test in larger samples whether the current pattern of effects is limited to self-reported attachment.

The finding that children with more secure attachment expectations seek maternal support faster is in line with attachment theory's prediction that children who expect their caregivers to be available and responsive to their needs have a stronger tendency to seek caregivers' support when confronted with stress (Bowlby, 1969; 1988; Cassidy, 1994). This 
finding converges with Bosmans and colleagues'(2015) demonstrated link between higher confidence in maternal support and faster support-seeking using a similar design. Moreover, it is in line with previous questionnaire studies in middle childhood that found attachment security to be linked to the use of more constructive coping techniques as reported by mother, including seeking support from others (Contreras, Kerns, Weimer, Gentzler, \& Tomich, 2000; Kerns et al., 2007). The current study adds to these findings by providing behavioral support for the link between secure attachment and the use of support-seeking, and by demonstrating that it occurs during elevated levels of stress, suggesting that this support-seeking behavior serves as a coping-strategy.

As predicted, both more avoidant and more anxious attachment expectations were linked to waiting longer before seeking maternal support. For avoidant attachment, this direction of effect is in line with previous studies in infancy and adulthood which found that (higher scores on) attachment avoidance was linked to a reduced tendency to seek attachment figure's proximity and support (Ainsworth et al., 1978; Collins \& Feeney, 2000; Dewitte et al., 2008; Fraley \& Shaver, 1998). The finding for anxious attachment, however, seemingly contradicts previous studies in infancy and adulthood which found an increased tendency to seek attachment figure's proximity and support in (more) ambivalent/anxious individuals (Ainsworth et al., 1978; Dewitte et al., 2008). Yet, it should be noted that observational research showed that (higher scores on) ambivalent/anxious attachment are not necessarily related to straightforward requests for attachment-figure support (Collins \& Feeney, 2000; Fraley \& Shaver, 1998), and sometimes even with avoidance of the attachment figure (Ainsworth et al., 1978; Main \& Cassidy, 1988). In this regard, it is important to note that children's attachment-related behavior patterns are not trait-like cross-situationally stable patterns, but rather situation-specific signs of underlying attachment-related beliefs and expectations (Ainsworth et al., 1978; Sroufe, Fox, \& Pancake, 1983; Waters \& Sroufe, 1983). 
It is thus well possible that in different contexts, or when given different opportunities for seeking support, attachment anxiety can be related to increased support-seeking. Future research could attempt to investigate when attachment anxiety is related to increased or decreased support-seeking behavior, and which processes underlie these behaviors.

The current study's finding that seeking maternal support more slowly in middle childhood is related to increased depressive symptoms if children experienced more life events, adds to previous work that demonstrates the developmental importance of effective stress-regulatory interactions in the middle childhood mother-child relationship (Mezulis et al., 2006). More specifically, the current study was the first to demonstrate a link between middle childhood support-seeking towards mother and an increase in depressive symptoms over time. The current results suggest that, in middle childhood, children's own supportseeking behavior might play a protective role against the development of later depressive symptoms. This is in line with the idea that, in middle childhood, children play an increasingly active role in the stress-regulation process by more actively seeking attachment figures' support when needed (Mayseless, 2005).

This longitudinal effect supports recent claims that middle childhood attachment has too long been incorrectly considered as the least important age-period to study attachment development (Bosmans \& Kerns, 2015). Instead, it appears that during this age-period children need to learn the skills required to actively involve attachment figures as a source for support in order to be able to protect themselves from stress experienced in adolescence. Two additional findings in the current study are relevant with regard to this idea. First, adolescents report more depressive symptoms and more insecure attachment with increasing age. This is not surprising because of increased depression prevalence in adolescence (Lee et al., 2010) and because of increased conflicts in parent-adolescent relationships (Paikoff \& BrooksGunn, 1991) that affect insecure adolescents' attachment expectations (Bosmans, Van de 
Walle, Goossens, \& Ceulemans, 2014). Second, insecure attachment expectations and depressive symptoms were strongly related. Although, this relationship is likely affected by reporter bias, it confirms clinical studies that have shown insecure attachment expectations to be an essential mechanism in the development of adolescent depression (e.g., Diamond et al., 2010). Altogether, this suggests that adolescents need secure attachment relationships as a critical buffer against depressive symptoms. Consequently, it seems reasonable to assume that attachment development in middle childhood leads to the skills adolescents need to be able to continue considering parents as a safe haven to turn to in spite of the turbulence so typical in parent-child relationships during adolescence.

Intriguingly, there was a marginally significant positive effect of slower proximity seeking on depressive symptoms in the absence of life events. This finding seems in line with the idea that insecure attachment is a protective response to an insensitive environment (Hinde, 1988). Although one should be careful to interpret this trend, this strategy might help avoiding the disappointing experience of parents' inability to provide care, which increasingly makes children feel less depressed. However, as soon as these children encounter events that warrant support, this strategy seems to collapse and to aggravate the depressogenic effect of the distress related to these events.

\section{Limitations}

The current study significantly adds to previous studies on attachment and stressregulation in middle childhood by providing the first evidence that children's attachment expectations are linked to children's support-seeking behavior in middle childhood, and that middle childhood proximity-seeking behavior influences the development of depressive symptoms out of stressful life events. Nevertheless, some limitations should be taken into account when interpreting the results. 
A first limitation concerns the large variation in the duration of Reunion 1, due to which a recalculation of the variable representing the time to support-seeking was required. Although analyses suggest this did not affect the results, future research should try to overcome this issue. One solution for this issue might be to work with longer or non-restricted puzzle time (e.g., Bosmans et al., 2015). However, we tried this in a pilot study and it ended up with children working up to 40 minutes. This created other methodological problems and was difficult to include in the current already time-consuming design. Moreover, it should be noted that the current results converge with those of Bosmans and colleagues' (2015). This suggests that the results are probably independent of the available puzzle time. Another option might be to work with a fixed duration of the reunion in which the experimenter signals to the mother that she should leave the room, instead of letting mother decide when to end the reunion.

Second, the current results rely solely on self-reported anxious and avoidant attachment. One issue with self-report attachment-measures is that they tend to lead to an underestimation of attachment insecurity, because not all insecure individuals describe themselves as insecure (Ainsworth, 1985). Note, however, that recent research in middle childhood revealed associations between self-reported attachment measures and narrative assessments of children's secure base scriptedness (Psouni \& Apetroaia, 2014), suggesting that -at least in middle childhood- children might validly report on their attachment expectations. Nevertheless, future research should attempt to replicate the current findings using different methods for assessing attachment-anxiety and -avoidance, but also assessing disorganized attachment.

Third, 17 subjects were left out of the analyses due to procedural errors. This suggests that the observation procedure should be further optimized in future research. The main cause 
was children's failure to comply with the puzzle rules. One solution could be to use a computerized version of the puzzle task.

Finally, the high number of participants who dropped out substantially reduced the sample size that could be used for the longitudinal analyses. One of the reasons for these dropouts might have been that we might have waited too long to contact the families again and that the invitation to the online questionnaire tool was sent through email which could easily be neglected. Perhaps, maintaining better contact with the families between measurement periods could have prevented this. On the one hand, it is reassuring that the dropouts appeared to be random and were not significantly linked to the study variables or the socio-demographic variables. However, it remains to be seen whether the results can be replicated in samples where risk for dropout is better controlled. On the other hand, the small sample size affected the power of the interaction analysis $(1-\beta=.61)$. So for future research, it should be recommended to use a larger sample to test whether this effect replicates. Lastly, the dropouts limited the possibility to test more complicated models, including for example the effect of attachment (in)stability.

\section{Conclusion}

In sum, the current study was the first to investigate the link between middle childhood anxious and avoidant attachment and support-seeking behavior towards mother, and how this behavior influences the future development of depressive symptoms. Results showed that, during stress, children with higher self-reported anxious and avoidant attachment seek maternal support more slowly, and that children who more slowly seek support have a larger risk to develop depressive symptoms out of stressful life events. This way, this study makes a significant contribution to the growing literature on attachment and stress-regulation 
in middle childhood, and adds to previous work demonstrating the importance of stress regulation within the middle childhood mother-child attachment relationship.

\section{References}

Aiken, L. S., \& West, S. G. (1991). Multiple regression: Testing and interpreting interactions. Newbury Park, CA: Sage.

Ainsworth, M. D. S. (1973). The development of infant-mother attachment. In B.M. Caldwell \& H. N. Ricciuti (Eds.), Review of child development research (pp. 1-94). Chicago, IL: University of Chicago Press.

Ainsworth, M. D. S. (1985). Attachments across the life-span. Bulletin of the New York Academy of Medicine, 61(9), 792-812.

Ainsworth, M. D. S., Blehar, M. C., Waters, E., \& Wall, S. (1978). Patterns of attachment: A psychological study of the strange situation. Hillsdale, NJ: Erlbaum.

Bosmans, G. \& Kerns, K.A. (2015). Attachment in middle childhood: Progress and prospects. Manuscript submitted for publication.

Bosmans, G., Van de Walle, M., Goossens, L., \& Ceulemans, E. (2014). (In)variability of attachment in middle childhood: Secure base script evidence in diary data. Behaviour Change, 31(4), 225-242. doi:10.1017/bec.2014.18

Bosmans, G., Braet, C., Heylen, J., \& De Raedt, R. (2015). Children's attentional processing of mother and proximity seeking. Manuscript submitted for publication.

Bowlby, J. (1969). Attachment and loss: Vol. 1. Attachment. New York, NY: Basic. 
Bowlby, J. (1973). Attachment and loss: Vol. 2. Separation: Anxiety and anger. New York, NY: Basic.

Bowlby, J. (1988). A secure base: Clinical applications of attachment theory. London: Routledge.

Brenning, K., Soenens, B., Braet, C., \& Bosmans, G. (2011). An adaptation of the Experiences in Close Relationships Scale-Revised for use with children and adolescents. Journal of Social and Personal Relationships, 28(8), 1048-1072. doi:10.1177/0265407511402418

Cassidy, J. (1994). Emotion regulation: Influences of attachment relationships. Fox, N. The development of emotion regulation, Monographs of the Society for Research in Child Development 59[2-3, Serial No. 240], 228-249. .

Claus, L. (2004). Vragenlijst Meegemaakte Gebeurtenissen. Herziene Handleiding.

Collins, N. L., \& Feeney, B. C. (2000). A safe haven: An attachment theory perspective on support seeking and caregiving in intimate relationships. Journal of Personality and Social Psychology, 78(6), 1053-1073. doi:10.1037//0022-3514.78.6.1053

Compas, B. E., Connor-Smith, J. K., Saltzman, H., Thomsen, A. H., \& Wadsworth, M. E. (2001). Coping with stress during childhood and adolescence: Problems, progress, and potentional in theory and research. Psychological Bulletin, 127(1), 87-127. doi:10.1037//0033-2909.127.1.87

Contreras, J. M., Kerns, K. A., Weimer, B. L., Gentzler, A. L., \& Tomich, P. L. (2000). Emotion regulation as a mediator of associations between mother-child attachment and peer relationships in middle childhood. Journal of Family Psychology, 14(1), 111124. doi:10.1037//0893-3200.14.1.111 
Cuijpers, P., \& Smit, F. (2002). Excess mortality in depression: A meta-analysis of community studies. Journal of Affective Disorders, 72(3), 227-236. doi:10.1016/S0165-0327(01)00413-X

Dawson, M. E., Schell, A. M., \& Filion, D. L. (2007). The electrodermal system. In J.T. Cacioppo, L. G. Tassinary, \& G. G. Berntson (Eds.), Handbook of psychophysiology (3rd ed., pp. 159-181). New York: Cambridge University Press.

Dewitte, M., De Houwer, J., Goubert, L., \& Buysse, A. (2010). A multi-modal approach to the study of attachment-related distress. Biological Psychology, 85(1), 149-162. doi:10.1016/j.biopsycho.2010.06.006

Dewitte, M., De Houwer, J., Buysse, A., \& Koster, E. H. (2008). Proximity seeking in adult attachment: Examining the role of automatic approach-avoidance tendencies. British Journal of Social Psychology, 47, 557-573. doi:10.1348/014466607X265148

Diamond, G. S., Wintersteen, M. B., Brown, G. K., Diamond, G. M., Gallop, R., Shelef, K. et al. (2010). Attachment-Based Family Therapy for adolescents with suicidal ideation: A randomized controlled trial. Journal of the American Academy of Child and Adolescent Psychiatry, 49(2), 122-131. doi:10.1016/j.jaac.2009.11.002

Diamond, L. M., Hicks, A. M., \& Otter-Henderson, K. (2006). Physiological evidence for repressive coping among avoidantly attached adults. Journal of Social and Personal Relationships, 23(2), 205-229. doi:10.1177/0265407506062470

Dubois-Comtois, K., Moss, E., Cyr, C., \& Pascuzzo, K. (2013). Behavior problems in middle childhood: the predictive role of maternal distress, child attachment, and mother-child interactions. Journal of Abnormal Child Psychology, 41(8), 1311-1324.

doi:10.1007/s 10802-013-9764-6 
Easterbrooks, M. A., Davidson, C. E., \& Chazan, R. (1993). Psychosocial risk, attachment, and behavior problems among school-aged children. Development and Psychopathology, 5(3), 389-402. doi:10.1017/S095457940000448X

Eldar, S., Ricon, T., \& Bar-Haim, Y. (2008). Plasticity in attention: Implications for stress response in children. Behaviour Research and Therapy, 46(4), 450-461. doi:10.1016/j.brat.2008.01.012

Fraley, R. C., \& Shaver, P. R. (1998). Airport separations: A naturalistic study of adult attachment dynamics in separating couples. Journal of Personality and Social Psychology, 75(5), 1198-1212. doi:10.1037/0022-3514.75.5.1198

Fraley, R. C., Waller, N. G., \& Brennan, K. A. (2000). An item response theory analysis of self-report measures of attachment. Journal of Personality and Social Psychology,(78), 350-365. doi:10.1037/0022-3514.78.2.350

Grossmann, K., Grossmann, K. E., Spangler, G., Suess, G., \& Unzner, L. (1985). Maternal sensitivity and newborns orientation responses as related to quality of attachment in Northern Germany. Monographs of the Society for Research in Child Development, 50(1-2), 233-256. doi:10.2307/3333836

Gunnar, M. R., Wewerka, S., Frenn, K., Long, J. D., \& Griggs, C. (2009). Developmental changes in hypothalamus-pituitary-adrenal activity over the transition to adolescence: Normative changes and associations with puberty. Development and Psychopathology, 21(1), 69-85. doi:10.1017/S0954579409000054

Gunnar, M. R., Talge, N. M., \& Herrera, A. (2009). Stressor paradigms in developmental studies: What does and does not work to produce mean increases in salivary cortisol. Psychoneuroendocrinology, 34(7), 953-967. doi:10.1016/j.psyneuen.2009.02.010

Hankin, B. L., Badanes, L. S., Abela, J. R. Z., \& Watamura, S. E. (2010). HypothalamicPituitary-Adrenal Axis dysregulation in dysphoric children and adolescents: Cortisol 
reactivity to psychosocial stress from preschool through middle adolescence.

Biological Psychiatry, 68(5), 484-490. doi:10.1016/j.biopsych.2010.04.004

Hayes, A. F. (2013). Introduction to mediation, moderation, and conditional process analysis. New York: Guilford Press.

Hinde, R. (1988). Continuities and discontinuities. In M. Rutter (Ed.), Studies of psychosocial risk: The power of longitudinal data (pp. 367-384). Cambridge, UK: Cambridge University Press.

Kandel, E. R. (1999). Biology and the future of psychoanalysis: A new intellectual framework for psychiatry revisited. American Journal of Psychiatry, 156(4), 505-524.

Kerns, K. A., Abraham, M. M., Schlegelmilch, A., \& Morgan, T. A. (2007). Mother-child attachment in later middle childhood: Assessment approaches and associations with mood and emotion regulation. Attachment \& Human Development, 9(1), 33-53. doi:10.1080/14616730601151441

Kerns, K. A., \& Brumariu, L. E. (in press). Attachment in middle childhood. To appear in P.R. Shaver \& J. Cassidy (Eds.), Handbook of Attachment (3rd ed.).

Kim, Y. (2006). Gender, attachment, and relationship duration on cardiovascular reactivity to stress in a laboratory study of dating couples. Personal Relationships, 13(1), 103-114. doi:10.1111/j.1475-6811.2006.00107.x

Larsen, J. T., Berntson, G. G., Poehlman, K. M., Ito, T. A., \& Cacioppo, J. T. (2010). The psychophysiology of emotion. In M. Lewis, J. M. Haviland-Jones, \& L. Feldman Barrett (Eds.), Handbook of emotions (3rd ed., pp. 180-195).

Lee, A., Hankin, B. L., \& Mermelstein, R. J. (2010). Perceived social competence, negative social interactions, and negative cognitive style predict depressive symptoms during adolescence. Journal of Clinical Child and Adolescent Psychology, 39(5), 603-615. doi:10.1080/15374416.2010.501284 
Lewinsohn, P. M., Solomon, A., Seeley, J. R., \& Zeiss, A. (2000). Clinical implications of "subtreshold" depressive symptoms. Journal of Abnormal Psychology, 109(2), 345351. doi:10.1037/0021-843X.109.2.345

Luijk, M. P. C. M., Saridjan, N., Tharner, A., van Ijzendoorn, M. H., Bakermans-Kranenburg, M. J., Jaddoe, V. W. V. et al. (2010). Attachment, depression, and cortisol: Deviant patterns in insecure-resistant and disorganized infants. Developmental Psychobiology, 52(5), 441-452. doi:10.1002/dev.20446

Main, M. (1990). Cross-cultural studies of attachment organization - Recent studies, changing methodologies, and the concept of conditional strategies. Human Development, 33(1), 48-61. doi:10.1159/000276502

Main, M., \& Cassidy, J. (1988). Categories of response to reunion with the parent at age 6: Predictable from infant attachment classifications and stable over a 1-month period. Developmental Psychology, 24(3), 415-426. doi:10.1037/0012-1649.24.3.415

Main, M., Kaplan, N., \& Cassidy, J. (1985). Security in infancy, childhood, and adulthood - A move to the level of representation. Monographs of the Society for Research in Child Development, 50(1-2), 66-104. doi:10.2307/3333827

Maunder, R. G., Lancee, W. J., Nolan, R. P., Hunter, J. J., \& Tannenbaum, D. W. (2006). The relationship of attachment insecurity to subjective stress and autonomic function during standardized acute stress in healthy adults. Journal of Psychosomatic Research, 60(3), 283-290. doi:10.1016/j.jpsychores.2005.08.013

Mayseless, O. (2005). Ontogeny of attachment in middle childhood: Conceptualization of normative changes. In K.A. Kerns \& R. A. Richardson (Eds.), Attachment in middle childhood (pp. 1-23). New York, NY: The Guilford Press.

Mezulis, A. H., Hyde, J. S., \& Abramson, L. Y. (2006). The developmental origins of cognitive vulnerability to depression: Temperament, parenting, and negative life 
events in childhood as contributors to negative cognitive style. Developmental Psychology, 42(6), 1012-1025. doi:10.1037/0012-1649.42.6.1012

Mikulincer, M., \& Shaver, P. R. (2008). Adult attachment and affect regulation. In J. Cassidy \& P. R. Shaver (Eds.), Handbook of Attachment: Theory, Research, and Clinical Applications (2 ed., pp. 503-531). New York: Guilford Press.

Paikoff, R. L., \& Brooks-Gunn, J. (1991). Do parent-child relationships change during puberty? Psychological Bulletin, 110(1), 47-66. doi:10.1037/0033-2909.110.1.47

Petersen, A. C., Crockett, L., Richards, M., \& Boxer, A. (1988). A self-report measure of pubertal status - reliability, validity, and initial norms. Journal of Youth and Adolescence, 17(2), 117-133. doi:10.1007/BF01537962

Poulin, C., Hand, D., \& Boudreau, B. (2005). Validity of a 12-item version of the CES-D used in the National Longitudinal Study of Children and Youth. Chronic Diseases in Canada, 26(2-3), 65-72.

Psouni, E., \& Apetroaia, A. (2014). Measuring scripted attachment-related knowledge in middle childhood: the Secure Base Script Test. Attachment \& Human Development, 16(1), 22-41. doi:10.1080/14616734.2013.804329

Radloff, L. S. (1977). The CES-D scale: a self-report depression scale for research in the general population. Applied Psychological Measurement, 1, 385-401. doi:10.1177/014662167700100306

Shirtcliff, E. A., Dahl, R. E., \& Pollak, S. D. (2009). Pubertal development: Correspondence between hormonal and physical development. Child Development, 80(2), 327-337. doi:10.1111/j.1467-8624.2009.01263.x

Sroufe, L. A., Fox, N. A., \& Pancake, V. R. (1983). Attachment and dependency in developmental perspective. Child Development, 55(6), 1615-1627. doi:10.1111/j.1467-8624.1983.tb00078.x 
Sroufe, L. A., \& Waters, E. (1977). Attachment as an organizational construct. Child Development,(48), 1184-1199. doi:10.1111/j.1467-8624.1977.tb03922.x

Steele, H., \& Steele, M. (2014). Attachment disorders: Theory, research and treatment considerations. In M. Lewis \& K. D. Rudolph (Eds.), Handbook of Developmental Psychopathology (3rd ed., pp. 357-370). New York: Springer US.

Thompson, R. A. (1994). Emotion regulation: A theme in search of definition. Monographs of the Society for Research in Child Development, 59(2-3), 25-52. doi:10.1111/j.15405834.1994.tb01276.x

Veerman, J. M., ten Brink, L. T., van der Horst, H., \& Koedoot, P. (1993). Vragenlijst Meegemaakte Gebeurtenissen. Herziene handleiding [Questionnaire of Life Events. Revised Manual]. Amsterdam: Pedologisch Instituut.

Waters, E., \& Sroufe, L. A. (1983). Social competence as a developmental construct. Developmental Review, 3(1), 79-97.

Zisner, A. R., \& Beauchaine, T. P. (in press). Psychophysiological methods and developmental psychopathology. To appear in D. Cicchetti (Ed.), Developmental psychopathology (3rd ed). Hoboken, NJ: Wiley.

\section{Acknowledgement}


Table 1

Means, Standard Deviations, and Correlations between the Study's Main Variables, Age, and Gender at Time point 1 and Follow-up.

Time point $1(\mathrm{~N}=98)$

$\begin{array}{lllllllllll}2 & 3 & 4 & 5 & 6 & 7 & 8 & 9 & 10 & 11 & 12\end{array}$

1. Time to Support-Seeking -

2. Attachment Anxiety $.27 *$

3. Attachment Avoidance $.26 * * \quad .60 * * * \quad-$

4. Depressive Symptoms

$.13 \quad .50 * * * \quad 34 * * * \quad-$

5. Pubertal Development $.21 *$

Follow-up ( $\mathrm{N}=48)$

6. Attachment Anxiety

$.09 \quad .34 *$

$.43 * * \quad .31 * \quad .23$

7. Attachment Avoidance

.03

$.25 \dagger$

$.48 * * * \quad .08$

8. Depressive symptoms

$.02 \quad .06$

9. Number of Life events

$.19 \quad .24$

.21

$.69 * * * \quad-$

Demographic variables

\begin{tabular}{|c|c|c|c|c|c|c|c|c|c|c|c|c|}
\hline 10. Age & .05 & .01 & .02 & -.01 & $.30 * *$ & - & - & - & - & - & & \\
\hline 11. Age FU & - & - & - & - & - & $.35^{*}$ & $.32 *$ & $.30 *$ & $.24 \dagger$ & $.91 * * *$ & - & \\
\hline 12. Gender & -.10 & .03 & -.06 & .01 & $-.32 * *$ & .02 & .06 & -.15 & -.17 & .07 & .02 & - \\
\hline$S D$ & 104.17 & 0.79 & 0.88 & 4.94 & 2.81 & 0.89 & 1.27 & 4.84 & 3.75 & 0.92 & 1.02 & - \\
\hline
\end{tabular}

Note. $* * * p<.001 ; * * p<.01 ; * p<.05 ; \dagger p<.10$; Gender is dummy coded (girl=0, boy=1); Age is cross-sectional (at T1 for T1-variables and at FU for FU-variables) 
Figures

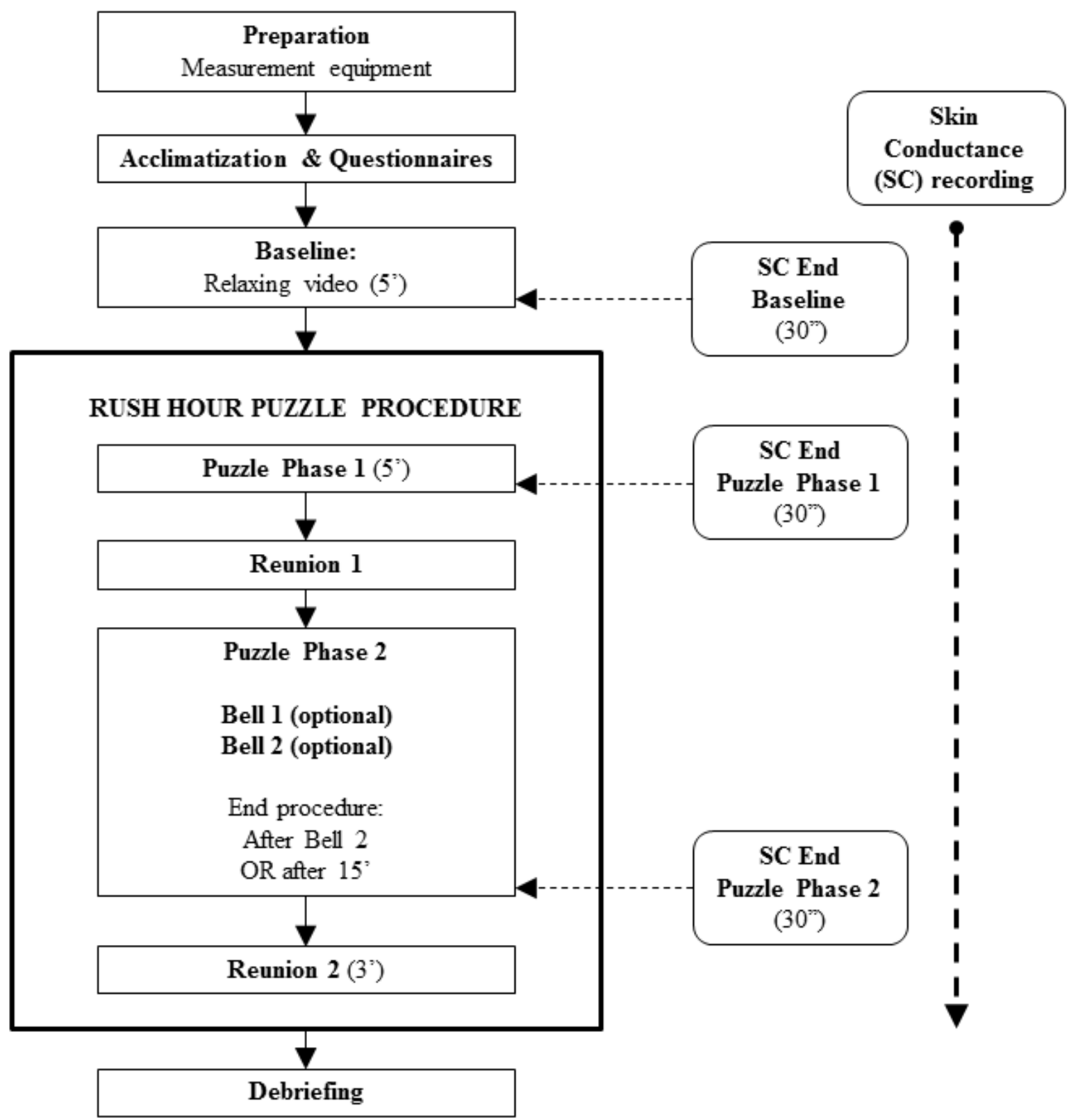

Figure 1. Overview procedure at Time point 1 


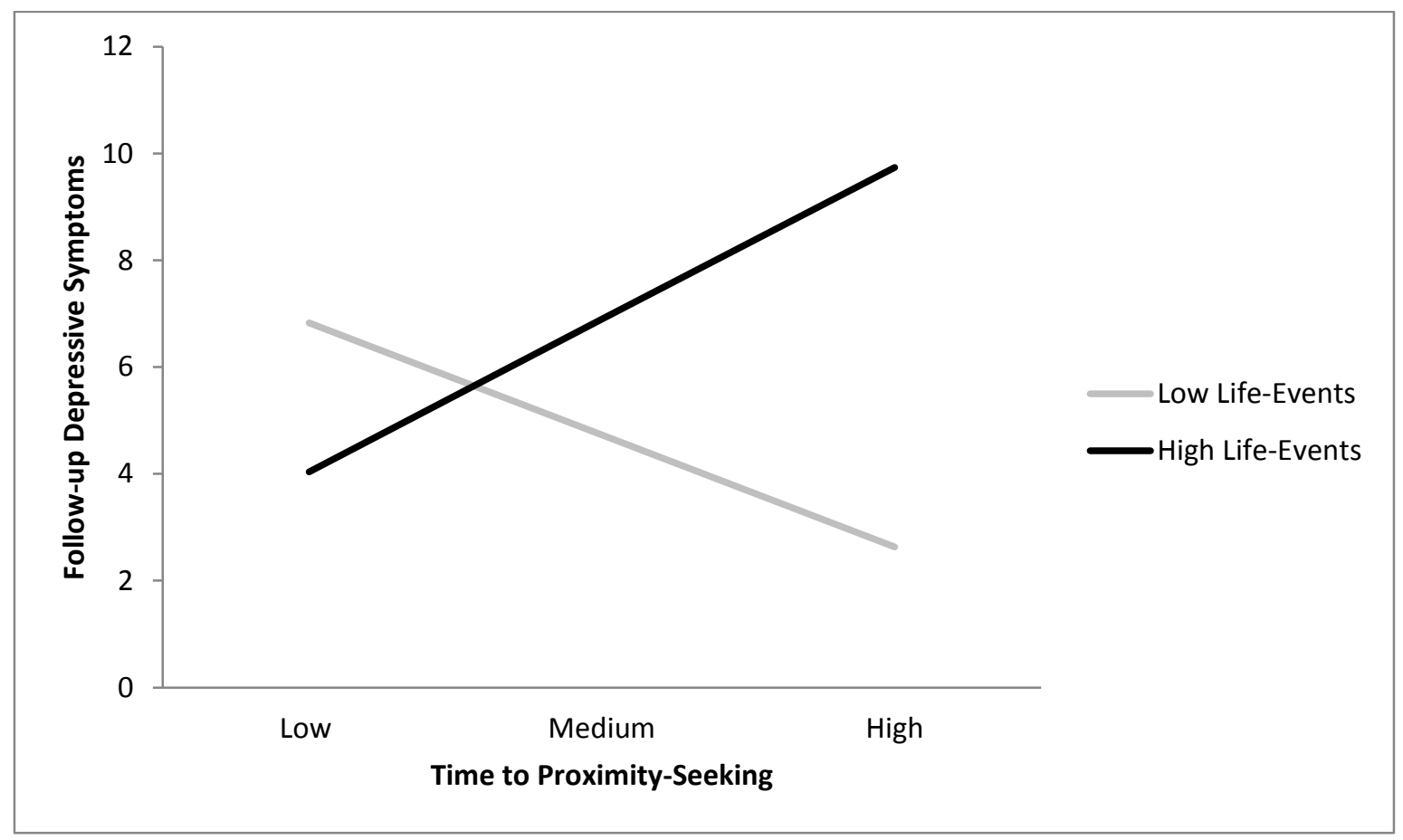

Figure 2. Interaction between Time to Support-Seeking and Experienced Life Events on Follow-up Depressive symptoms 